\title{
The Impact of Teaming and Cognitive Style on Student Perceptions of Design Ideation Outcomes
}

\section{Dr. Kathryn W. Jablokow, Pennsylvania State University, Great Valley}

Dr. Kathryn Jablokow is an Associate Professor of Mechanical Engineering and Engineering Design at Penn State University. A graduate of Ohio State University (Ph.D., Electrical Engineering), Dr. Jablokow's teaching and research interests include problem solving, invention, and creativity in science and engineering, as well as robotics and computational dynamics. In addition to her membership in ASEE, she is a Senior Member of IEEE and a Fellow of ASME. Dr. Jablokow is the architect of a unique 4-course module focused on creativity and problem solving leadership and is currently developing a new methodology for cognition-based design. She is one of three instructors for Penn State's Massive Open Online Course (MOOC) on Creativity, Innovation, and Change, and she is the founding director of the Problem Solving Research Group, whose 50+ collaborating members include faculty and students from several universities, as well as industrial representatives, military leaders, and corporate consultants.

Mr. Wesley Teerlink, Penn State University

Dr. Seda Yilmaz, Iowa State University

Dr. Yilmaz is an Assistant Professor of Industrial Design. She teaches design studios and lecture courses on developing creativity and research skills. Her current research focuses on identifying impacts of different factors on ideation of designers and engineers, developing instructional materials for design ideation, and foundations of innovation. She often conducts workshops on design thinking to a diverse range of groups including student and professional engineers and faculty member from different universities. She received her PhD degree in Design Science in 2010 from University of Michigan. She is also a faculty in Human Computer Interaction Graduate Program and the ISU Site Director for Center for e-Design.

Dr. Shanna R. Daly, University of Michigan

Eli M. Silk, Rutgers, The State University of New Jersey 


\title{
The Impact of Teaming and Cognitive Style on Student Perceptions of Design Ideation Outcomes
}

\begin{abstract}
Ideation is a key component of the design process, which often takes place in team settings. The team approach to design requires the involvement of all parties demonstrating the use of their expertise and knowledge in the area. Teaming has been shown to have both positive and negative impacts on ideation activities ${ }^{1-5}$. Cognitive style - or the stable, preferred way that people manage and seek to bring about change - helps us understand the different ways in which people solve problems individually and as part of a team. When team members' cognitive styles are diverse, creating an effect known as cognitive gap, the team may experience the advantages of approaching problems in diverse ways, but the likelihood of conflicts and misunderstandings increases ${ }^{6}$.
\end{abstract}

This study investigated the relationship between cognitive style and the perceptions of students working in teams about their own ideation. Through the analysis of reflection surveys from 202 pre-engineering, engineering, and design students participating in an ideation study, we explored the following questions: (1) how does working in teams impact students' perceptions of their own ideation?; and (2) how do team members' cognitive styles impact their perceptions of their ideation and team contributions? In this paper, we report on the significant correlations between cognitive style and changes in students' perceptions about their ideation creativity, diversity, elaboration, and difficulty, as well as our exploration of the impact of teaming on these perceptions.

\subsection{Introduction}

Concept generation, or ideation, occurs most notably in the early stages of design, when designers propose solutions that they will later explore and refine (or reject). The role of ideation in design is to generate promising design concepts to pursue; many and diverse ideas increase the potential for successful design outcomes by increasing the number of possibilities available during concept evaluation and selection ${ }^{7,8}$. This, in turn, increases the potential for generating a design solution that best meets a problem's given constraints.

The importance of ideation within the engineering design process is recognized equally in both academic and industrial settings ${ }^{9}$. The collaborative nature of engineering design is also wellestablished, ${ }^{9}$ with individuals of different personalities, technical backgrounds, and levels of experience coming together to meet shared design objectives. Following this real-world practice, engineering educators routinely put students in design teams to complete both simple and complex projects. However, in many cases, they do not consider the cognitive diversity among the students in forming those teams and often place them in teams in a randomized manner. One way of understanding an individual's preferred approach to ideation is to analyze their cognitive style, which provides insights into how much structure the individual prefers in solving problems and making decisions. In this paper, we focus on Adaption- Innovation (A-I) cognitive style and its assessment using $\mathrm{KAI}^{\circledR}$ (the Kirton Adaption-Innovation inventory) ${ }^{10}$, which has been rigorously validated and used in a wide variety of contexts, including engineering education ${ }^{6}$. 
Our goal for this study was to explore the extent to which teaming and cognitive style affect student perceptions about the creativity, diversity, and elaboration of their ideas, as well as their perceptions of the relative difficulty of generating ideas alone or with another person - i.e., in a team. We begin with some brief background about cognitive style, team ideation, and the use of perceptions in research, followed by discussions of our research questions, methods, analysis, and results. We close with our conclusions and comments on the limitations of this study and our plans for future work in this domain.

\subsection{Background and Previous Work}

\subsection{Cognitive Style and Ideation}

Kirton's Adaption-Innovation (A-I) theory ${ }^{6}$ is based on the key assumptions that (a) all individuals are creative (i.e., generate novelty); and (b) creativity can be characterized by four key variables: cognitive level, cognitive style, motive, and opportunity. In the current context, cognitive style is of primary interest, but it will be useful to first distinguish it from cognitive level to support later discussion. Cognitive level is defined as an individual's capacity for problem solving and creative behavior, as assessed through measures of both potential capacity (e.g., intelligence, aptitude, talent) and manifest capacity (e.g., knowledge, skills, expertise). In contrast, cognitive style is defined as one's stable, characteristic cognitive preference for seeking and responding to change, including the solution of problems ${ }^{6}$. Cognitive level is a unipolar construct (measured on a continuum from low to high), while cognitive style is a bipolar construct (measured on a continuum between two different, but equally valued, extremes).

Both cognitive level and cognitive style impact ideation ${ }^{6,11}$. First, cognitive level influences the degree of correctness, complexity, precision, and advancement of an individual's ideas, as well as the maximum number and speed with which those ideas are generated. For example, individuals with a higher cognitive level are likely to generate ideas faster and with more complex and advanced results that will also tend to reflect a higher degree of knowledge and skill $^{6}$. In contrast, cognitive style influences ideation based on the type and amount of structure a person prefers ${ }^{6}$. Using Kirton's Adaption-Innovation framework, cognitive style ranges along a continuous spectrum between highly adaptive and highly innovative preferences ${ }^{6}$, with mild and moderate degrees of those preferences in between. In general, individuals who are more adaptive prefer more structure (with more of it consensually agreed), while the more innovative prefer less structure (with less concern about consensus). These differences produce distinctive patterns of behavior (described further below), although an individual can (and does) behave in ways that are not preferred; this is called coping behavior, which comes at an extra cost to the individual (e.g., stress) $)^{6}$.

\subsection{Assessing Cognitive Style via the KAI}

In this study, cognitive style was assessed via the Kirton Adaption-Innovation inventory or $\mathrm{KAI}^{\circledR 6}$. For large general populations and across cultures, the distribution of KAI total scores forms a normal curve within the theoretical range of (32-160), with an observed mean of 95 (s.d. $=17$ ) and an observed range of (43-149); lower scores correspond to more adaptive cognitive styles, while higher scores correspond to more innovative styles. Through multiple validation studies, Kirton also identified three sub-scores that correspond to three sub-factors of cognitive 
style: Sufficiency of Originality (SO), Efficiency (E), and Rule/Group Conformity (R/G). These sub-factors are also normally distributed within the following theoretical ranges: SO (13-65), E (7-35), and $\mathrm{R} / \mathrm{G}(12-60)^{6}$. In describing each sub-factor below, we consider how it tends to impact ideation, both when working alone or in a team.

Sufficiency of Originality (SO): The SO sub-factor highlights differences between individuals in their preferred ways of generating and offering ideas ${ }^{6}$. The more adaptive tend to generate more highly detailed ideas that remain more closely connected to the original constraints of a problem, which results in their digging deeper into a particular region of the solution space in ideation. They may offer fewer ideas, not because they are blocked in their ideation, but because they are more careful in filtering their ideas first to make sure they match the problem constraints ${ }^{6,11}$. In contrast, more innovative individuals tend to generate ideas that challenge the problem definition and constraints, resulting in solutions that lie at the boundaries of the solution space or connect it with other tangential solution spaces. They may offer more ideas, not because they are more capable or have a greater capacity, but because they spend less time checking their ideas against the constraints of the problem and may even actively push against those constraints ${ }^{6,11}$.

Efficiency (E): The E sub-factor reflects an individual's preferred method for managing and organizing ideas in solving problems. The more adaptive prefer to define problems and their solutions carefully, paying closer attention to details and organization, while searching methodically for relevant information and solutions. In contrast, the more innovative often loosen and/or reframe the definition of a problem before they begin to resolve it, paying less attention to detail and taking a seemingly casual approach as they search for and carry out their solutions ${ }^{6,11}$.

Rule/Group Conformity $(R / G)$ : The R/G sub-factor reflects differences in the ways individuals manage the personal and impersonal structures in which their problem solving occurs. The more adaptive generally see standards, rules, traditions, and instructions (all impersonal structures) as enabling and useful, while the more innovative are more likely to see them as limiting and irritating. When it comes to personal structures (e.g., teams, partnerships), the more adaptive tend to devote more attention to group cohesion, while the more innovative are more likely to "stir up" a group's internal dynamics s,11. $^{6}$.

In terms of assessment, the internal reliability of KAI is high: 0.84 to 0.89 (mode of 0.87 ) over samples totaling nearly 3000 subjects from 10 countries $^{6}$. Numerous validity studies were completed for KAI, including content validation, factor analysis, and correlational analyses (see Kirton ${ }^{6}$ : pp. 82-84; also Appendix 6, Tables G \& J). In an engineering context, for example, Jablokow's study of graduate engineering students showed wide ranges of KAI scores among systems engineers, software engineers, and information scientists, respectively ${ }^{12}$, and DeFranco et al. ${ }^{13}$ reported similar findings among undergraduate engineering students.

\subsection{Cognitive Gap}

Whenever individuals work together, their cognitive differences become a relevant variable in that collaboration. Cognitive psychologists and other researchers use the term cognitive gap to describe these differences in cognitive level and/or cognitive style that can appear as any one of the following variations $\mathrm{s}^{6,14}$. 
a. A difference between the respective styles and/or levels of two individuals;

b. A difference between the style and/or level of an individual and the style mean or aggregate level of a group, respectively;

c. A difference between the respective style means or aggregate levels of two groups;

d. A difference between an individual or group and the requirements of a particular problem (i.e., between the respective styles and/or levels of each).

In general, these variations can be separated into two broad categories, namely: person-person gaps $(\mathrm{a}-\mathrm{c})$, and person-problem gaps $(\mathrm{d})^{14}$.

In terms of cognitive style (which is our primary interest here), it has been shown that the justnoticeable-difference between individuals is 10 points on the KAI scale. This means that individuals are unlikely to notice cognitive style differences when working with someone with a KAI score that is within 10 points of their own score (in either direction), while larger gaps are more likely to be problematic. As noted by Jablokow and Booth ${ }^{14}$ : "Gaps of 20 points or more between individuals have been shown to lead to significant problems, including poor communication, 'finger-pointing', misinterpretation of style differences as level deficiencies, and even loss of employment ${ }^{15-17}$. In such cases, a healthy dose of mutual respect and significant coping skills are necessary to bridge the gap effectively ${ }^{17,18}$, or failure can follow ${ }^{15,19}$. Even with such understanding and skills in place, collaboration between two such individuals will require more effort and will be more likely to cause stress than collaboration between individuals with closer styles; the larger the gap and the longer the individuals interact, the greater the effort (and any stress) will be. ${ }^{6,19,20,}$ For the most part, these effects have been studied in professional settings, with less attention to students in general and to engineers in particular. We aim to address this gap in research (at least in part) through the preliminary study described here.

\subsection{Ideation in Teams}

Many engineers work together in teams to generate new concepts ${ }^{21}$, and many successful firms focusing on design swear by the utility of teams with diverse backgrounds. Research in the behavioral sciences suggests that a group with diverse members of moderate expertise can outperform a group of homogeneous top experts ${ }^{22}$. However, a question not yet answered is this: does group interaction facilitate or detract from the successful ideation? Research in this area has focused a good deal on group brainstorming ${ }^{23}$, a method of collective idea generation where groups are instructed to generate as many different ideas as possible, avoid criticizing and assessing the ideas, and to combine and improve each other's ideas. Other methods derived from brainstorming vary: brainwriting ${ }^{24}$ allows team members to generate solutions in a written format and share the ideas anonymously, while the nominal group technique ${ }^{25}$ provides facilitation to rank each other's ideas after a brainstorming or a brainwriting activity. These three methods rely heavily on the notion that an environment in which ideas are allowed to flow freely will result in more creative output, compared to other systematic approaches to ideation that would facilitate a more structured environment to force the team to stay on track ${ }^{26}$.

In contrast, Paulus et al. ${ }^{1}$ have used the phrase "the illusion of group productivity" to describe how most members of teams using the brainstorming technique believe that groups routinely outperform equivalent sets of non-interacting productivity. Supporting this sense of doubt, research in cognitive science has demonstrated that a group of individuals who each worked privately exceeded the outcomes of a group composed of the same number of people who 
worked collaboratively ${ }^{2}$ - illustrating the phenomenon known as "process loss",27. A few studies conflict with these findings ${ }^{4}$ : for example, a "process gain" effect was found with some groups outperforming a combination of individuals ${ }^{28}$, as well as cases in which ideas, when shared, fostered new idea tracks, more complete layouts, and diverse synthesis ${ }^{29}$. In conclusion, while teaming effects on ideation have been explored to some extent, they have yielded mixed results, and the impact of similar and diverse cognitive styles within engineering teams in particular has not been fully explored in a design context.

\subsection{Using Perceptions of Ideation in Research}

Research on idea generation in groups has consistently shown that individuals' perception of their effectiveness in groups overestimates their actual effectiveness when using more objective measures of their performance ${ }^{21,30,31}$. Other research on idea generation has also suggested that designers are not always good judges of the effect of different interventions on their actual performance and may fail to recognize interventions that are hindering their performance ${ }^{32}$. Nevertheless, perceptions are relatively easy to collect and can provide some insight into the impact of different interventions when used appropriately. For instance, if individuals engage in idea generation under the same conditions but have different perceptions of their effectiveness, we can investigate factors that may explain their different perspectives. Cognitive style may be one potential explanatory variable that is worth considering. Relatedly, establishing reliable trends with respect to change in perceptions as a result of some intervention can provide a foundation for exploring the differences between those perceptions and more objective measures of performance as those additional measures are obtained. Our future work will consider more objective measures of performance in addition to measures of perception.

\subsection{Research Questions}

This study aims to answer the following general research questions in order to gain a better understanding of the impact of teaming and cognitive style on ideation in engineering and design education settings:

1. How does working in teams impact students' perceptions of their own ideation?

2. How do team members' cognitive styles impact their perceptions of their ideation and team contributions?

These questions are based on our recognition of the importance of both teaming and ideation in engineering education and practice, as well as evidence from previous research that cognitive style is an important factor in engineering problem solving.

\subsection{Research Methods}

\subsection{Participants}

The data in this study were gathered from a group of 202 pre-engineering and engineering students at Penn State University, Iowa State University, and the University of Michigan. The participant age ranged from 14 to 33 years old, and level of education ranged from high school to graduate school. Within this sample, 160 of the participants were male (79.2\%) and 42 were female (20.8\%). In terms of race, $78.8 \%$ were Caucasian, $10.8 \%$ were Asian, $6.9 \%$ were African American, and 3.4\% reported other ethnicities. A subgroup of 122 students had reliable KAI 
scores, as determined by a certificated KAI practitioner; this subgroup was used in the analyses involving cognitive style. Figure 1 shows the distribution of KAI total scores for this subgroup. Further, calculating the cognitive gaps between the members of student teams required that both team members have reliable KAI scores; a further subgroup of 74 students met these criteria and was used for cognitive gap analyses within 34 two-person teams and 2 three-person teams.

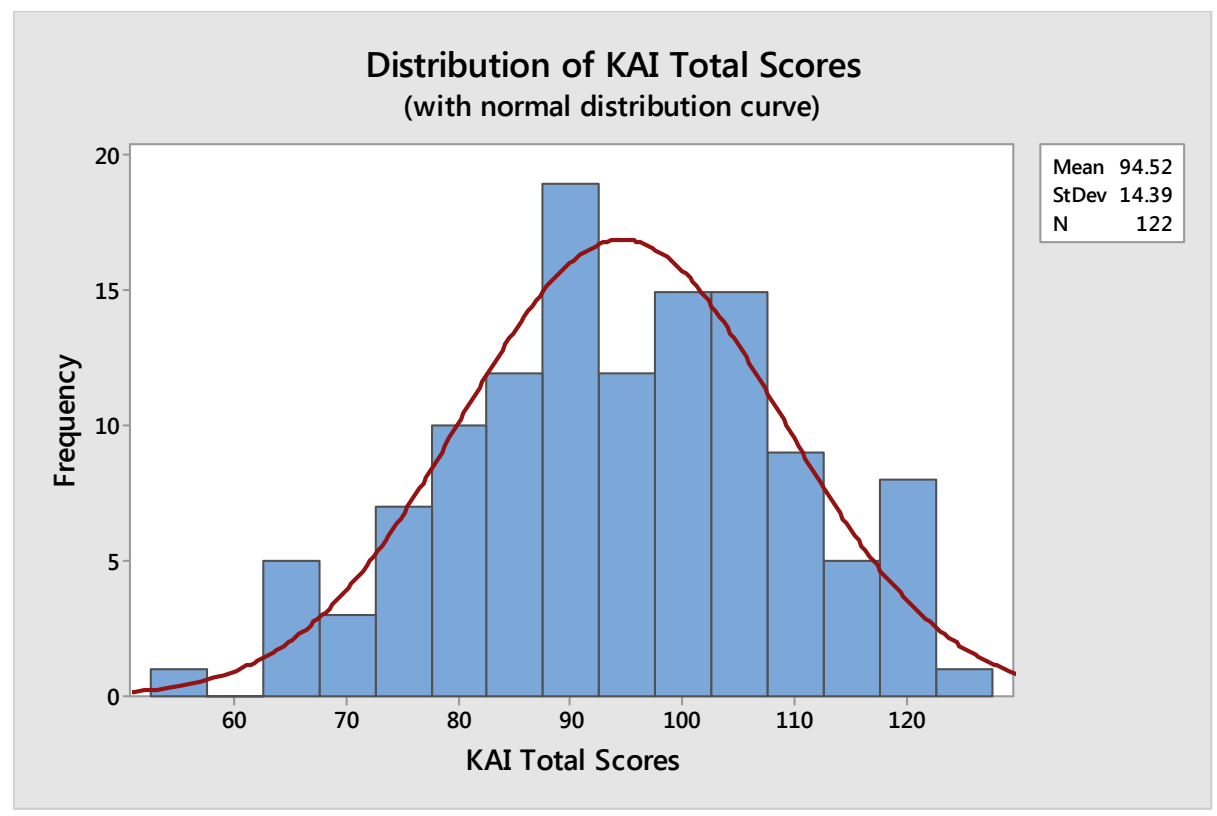

Figure 1. Distribution of reliable KAI scores for the sample [N=122]

\subsection{Data Collection and Analysis}

All students engaged in two separate ideation sessions - one individually (Session 1) and one in two-person or three-person teams (Session 2); they also completed the KAI ${ }^{\circledR}$ cognitive style inventory (individually, before the start of Session 1). For the first session, students were asked to generate solutions to a design problem individually and to provide words and sketches to describe their concepts. After this first ideation session, students were asked to generate ideas for a new problem in a two-person (or three-person) team; however, they were asked to record their ideas separately on their individual worksheets. For each idea generated in the team session, students were also asked to indicate which person from the team first verbalized each idea, as well as how much each person contributed to the idea's generation and development.

Four sets of data were collected during the study: 1) students' cognitive styles; 2) concepts generated during the individual ideation session (Session 1); 3) concepts generated during the teaming ideation session (Session 2); and 4) reflection surveys at the end of each ideation session. Following each ideation session, students completed a short reflection survey (individually) to provide insights into how they perceived their own ideation during the session. In particular, the students were asked to evaluate how creative, diverse, and elaborate their ideas were, as well as the level of difficulty they experienced generating ideas under each condition (See Appendix A for a copy of the reflection survey for the teaming ideation session). The following questions appeared and were assessed on a 7-point Likert scale: 
- How creative do you feel that your ideas were?

- How diverse, or different from each other, do you feel that your ideas were?

- How elaborate, detailed, or "fleshed-out," do you feel that your ideas were?

- How easy or difficult was it for you to come up with design ideas?

All of the questions above appeared on both the individual and team ideation surveys, while the following question was only used for the team ideation reflections:

- How much did working on a team make it easy or difficult for you to come up with design ideas?

Student perceptions were analyzed for differences between the individual and teaming ideation sessions. In addition, correlations between the students' perceptions (from both sessions) and their individual cognitive styles were examined to determine whether perceptions differed between the more adaptive (more structured) and the more innovative (less structured) problem solvers, as measured by KAI ${ }^{\mathbb{B}}$. The correlations among all of these data were calculated in $\mathrm{R}$ statistical software using Pearson correlations. Details about all these analyses and the corresponding results are provided and discussed in the next section.

\subsection{Results and Discussion}

\subsection{How does working in teams impact students' perceptions of their own ideation?}

To answer our first research question, we compared students' ideation perceptions during the individual ideation session (Session 1) to those during the teaming session (Session 2); as KAI was not involved, the full sample $(\mathrm{N}=202)$ was used. The change in ideation perception for each participant $(\Delta)$ was calculated by subtracting the individual reflection response (Session 1) from the teaming reflection response (Session 2). Therefore, positive $\Delta$ values indicate that the participant rated their creativity, diversity, elaboration, or difficulty in ideation higher during the teaming ideation session than the individual ideation session. The plots in Figure 2 show a histogram for the change in ideation perception for each question (creativity, diversity, elaboration, difficulty), with the mean for the sample indicated by a bold line.

A paired $t$-test showed statistically significant increases in the perceptions of creativity and elaboration from individual to teaming ideation, as seen in Table 1. As a group, the participants in the study felt a slight increase in how creative and elaborate they perceived their ideas to be. However, as the histograms of Figure 2 illustrate, a wide distribution still existed in these perceptions across the sample, with evidence of both positive and negative effects of team ideation. In answering our second research question, we explored whether cognitive style might be a factor that could help explain these different perceptions of teaming's effects. 
Table 1. Paired $t$-tests for Individual and Teaming Ideation Perceptions $(\mathrm{N}=202)$

\begin{tabular}{|l|l|l|l|l|l|l|l|l|}
\hline \multirow{2}{*}{$\begin{array}{l}\text { Statistics of } \\
\text { Perceptions }\end{array}$} & \multicolumn{2}{l|}{$\begin{array}{l}\text { Creativity } \\
(t=5.58 ; \mathrm{p}=0.000)\end{array}$} & \multicolumn{2}{l|}{$\begin{array}{l}\text { Diversity } \\
(t=1.36 ; \mathrm{p}=0.170)\end{array}$} & $\begin{array}{l}\text { Elaboration } \\
(t=4.33 ; \mathrm{p}=0.000)\end{array}$ & \multicolumn{2}{l|}{$\begin{array}{l}\text { Difficulty } \\
(t=1.45 ; \mathrm{p}=0.148)\end{array}$} \\
\cline { 2 - 9 } & Individ. & Teaming & Individ. & Teaming & Individ. & Teaming & Individ. & Teaming \\
\hline Mean & 4.49 & 5.16 & 4.53 & 4.75 & 3.93 & 4.41 & 4.44 & 4.68 \\
\hline SD & 1.44 & 1.35 & 1.55 & 1.51 & 1.35 & 1.32 & 1.54 & 1.50 \\
\hline
\end{tabular}

\section{Change in Perceptions $(\Delta)$ from Individual to Teaming Ideation}

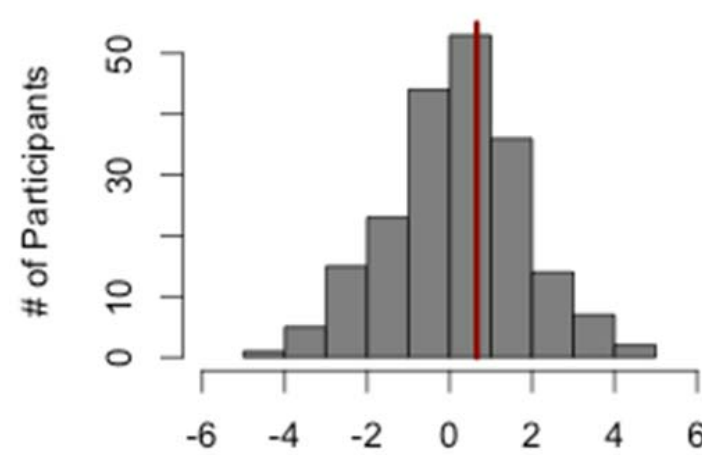

$\Delta$ Creativity

$(\mathrm{M}=0.66, \mathrm{SD}=1.66)$

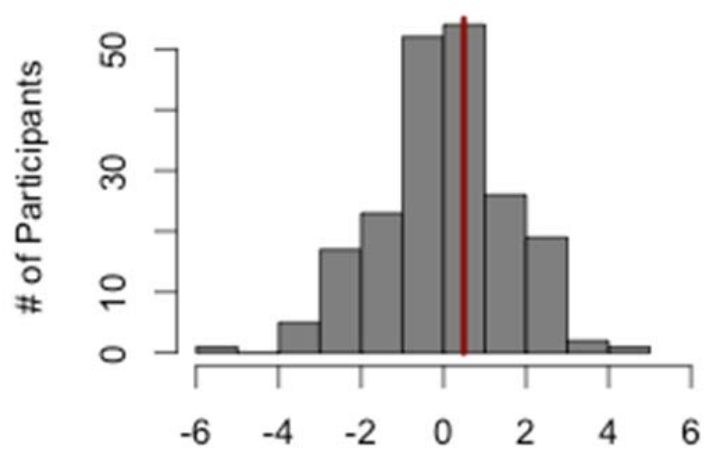

$\Delta$ Elaboration $(\mathrm{M}=0.49, \mathrm{SD}=1.60)$

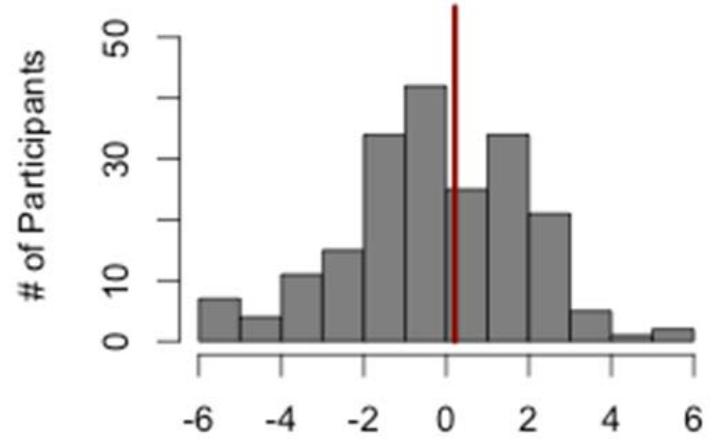

$\triangle$ Diversity

$(\mathrm{M}=0.21, \mathrm{SD}=2.20)$

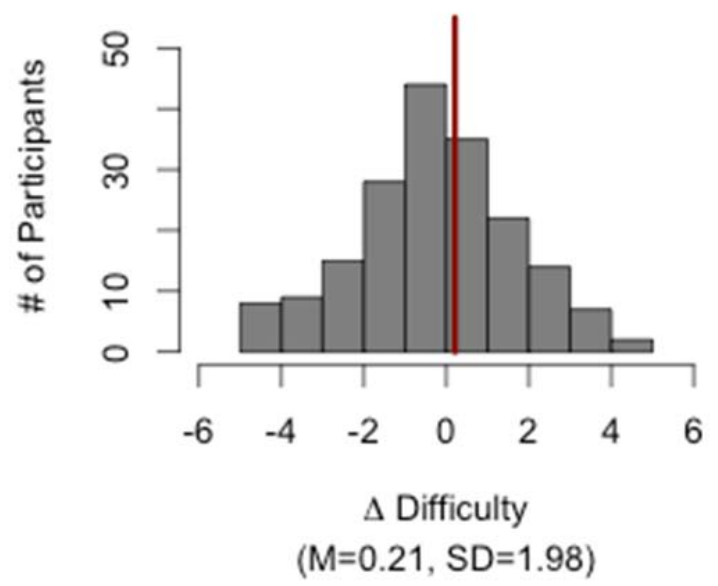

Figure 2. Histograms of the Changes in Perception from Individual to Teaming Ideation 


\subsection{How do team members' cognitive styles impact their perceptions of their ideation and team contributions?}

\section{Cognitive Style and Perceptions of Ideation}

To answer our second research question, we computed correlations between the changes in ideation perceptions (creativity, diversity, elaboration, and difficulty) and individual cognitive style (KAI total scores, plus SO, E, and R/G sub-scores), as shown in Table 2. We also computed correlations between cognitive style and the perceived impact on ideation of working on a team, as shown in Table 3. In both cases, the student sample with reliable KAI scores $(\mathrm{N}=122)$ was used.

Several weak $(|r|<0.3)$ but statistically significant correlations were revealed between cognitive style and changes in ideation perceptions (see Table 2), while no significant relationships were found between cognitive style and the perceived impact on ideation of working in a team (see Table 3). As shown in Table 2, the change in perception of ideation diversity ( $\Delta$ Diversity) correlated with KAI total score $(p \leq 0.005)$, as well as the sub-factors SO $(p \leq 0.005)$ and $\mathrm{R} / \mathrm{G}(p$ $\leq 0.01)$. In each case, the correlation was negative, meaning that people with a more innovative cognitive style (higher KAI) tended to view their ideas as less diverse when working in a team than when they worked alone, while those with a more adaptive cognitive style (lower KAI) tended to perceive their ideas as more diverse when working with someone else.

Table 2. Correlations for Change in Perceptions of Ideation vs. Cognitive Style [N=122]

\begin{tabular}{|l|l|l|l|l|}
\hline $\begin{array}{l}\text { Cognitive Style / } \\
\text { Change in Perceptions }\end{array}$ & KAI Total & SO & E & R/G \\
\hline$\Delta$ Creativity & -0.156 & -0.160 & $-0.192^{*}$ & -0.031 \\
\hline$\Delta$ Diversity & $-0.273^{\dagger}$ & $-0.255^{\dagger}$ & -0.077 & $-0.238^{* *}$ \\
\hline$\Delta$ Elaboration & 0.071 & -0.040 & $0.189^{*}$ & 0.082 \\
\hline$\Delta$ Difficulty & 0.054 & -0.020 & 0.068 & 0.092 \\
\hline
\end{tabular}

Table 3. Correlations for Perception of Teaming Impact vs. Cognitive Style [N=122]

\begin{tabular}{|l|l|l|l|l|}
\hline $\begin{array}{l}\text { Cognitive Style / } \\
\text { Perceptions }\end{array}$ & KAI Total & SO & E & R/G \\
\hline Impact of Teaming & 0.081 & 0.100 & -0.130 & 0.133 \\
\hline
\end{tabular}

All $\mathrm{p}>0.05$

These results align with expectations based on theory in the following way. In general, individuals who are more innovative are less cognizant of and sensitive to the boundaries or constraints placed on a problem, which leads them to generate ideas that may fall at the core, at the edge, or even outside the relevant paradigm for the current problem ${ }^{6}$. The more innovative often pride themselves in "connecting" ideas that span the current paradigm (or even multiple paradigms), which may give them a sense of greater diversity in their individual ideation. In contrast, individuals who are more adaptive appreciate and generally pay more attention to the constraints or boundaries of a problem, which leads them to "dig deep" with their ideas when ideating alone ${ }^{6}$. As a result, it is possible that being in a team makes the more innovative feel 
more constrained with respect to the problem paradigm, and therefore, less able to generate a diverse set of ideas, while the more adaptive feel enabled (or perhaps even compelled) to loosen their preferred tighter boundaries when working as a team, leading to a sense of greater diversity in ideation. Seeing these correlations with the $\mathrm{SO}$ and $\mathrm{R} / \mathrm{G}$ sub-scores makes sense in that these two sub-scores are most closely related to ideation and collaboration in problem solving, while the E sub-score is more closely linked to the preferred approach one takes in terms of order and method, which may not have played as great a part in this exercise.

Also as shown in Table 2, two interesting relationships were found between the E sub-factor and students' perceived changes in the creativity and elaboration of their ideas. The negative correlation with changes in perception of creativity, while weak $(|r|<0.2)$, indicates that the more adaptive students (lower KAI) tended to feel more creative when working in a team, while the more innovative students (higher KAI) were more likely to feel that being in a group decreased their creativity. One important note about these findings is that we do not know which behaviors the participants viewed as "creative". As discussed by Parkhurst ${ }^{33}$, despite a considerable body of research, a common definition for creativity does not exist, so its meaning may have varied widely between the participants of the study.

With changes in perceived elaboration of ideas, the correlation with cognitive style was positive, meaning that the more adaptive students tended to feel less elaborate when working in a group compared to their individual ideation, while the innovative felt more elaborate in their ideation in a team setting. This result aligns with theory, in that we might expect the more adaptive individuals, who prefer thoroughness and detail, to feel limited in their ability to explore that detail sufficiently when part of a team. Unlike the reflection questions for "creativity", the reflection question for elaboration used the words "detailed" and "fleshed out" as synonyms, making it less likely for widely varying definitions of the term to persist.

\section{Cognitive Style and Perceived Contribution to Ideation}

As shown in Appendix B, the idea sheets used in the teaming ideation session (Session 2) included a question about who initiated each idea and an evaluation of each individual's contribution to the idea (in \%). These latter evaluations were averaged over the ideation session i.e., the number of times that the participant initiated the idea was summed and divided by the total number of ideas generated to compute the percentage of ideas initiated by that individual. Instances where the participant indicated that both team members initiated the idea were counted as half an idea. A similar approach was used to calculate the average contribution of each individual (per idea). In the example shown in Table 4, Participant A took full credit for initiating Idea 1; both team members initiated Idea 2; and Idea 3 was initiated by Participant B (Participant A's teammate). Likewise, Participant A identified his/her percent contributions for each idea as $80 \%, 40 \%$, and $60 \%$, respectively. Therefore, in this example, Participant A generated $50 \%$ of the three ideas and had an average contribution of $60 \%$ per idea.

Correlations were also computed between idea initiations and perceived contributions (both \%) and cognitive style (KAI total score and sub-scores), with no statistically significant results, as shown in Table 5. Once again, the student sub-sample with reliable KAI scores $(\mathrm{N}=122)$ was used for these calculations. 
Table 4. Example: Idea Initiations and Perceived Contribution per Idea (\%) for Participant A

\begin{tabular}{|l|c|c|}
\hline Idea $\#$ & Idea Initiator & Perceived Contribution (\%) \\
\hline 1 & I initiated & 80 \\
\hline 2 & We both initiated & 40 \\
\hline 3 & My team member initiated & 60 \\
\hline Score & $100 \% \times(1+0.5+0) / 3=50 \%$ & $(80+40+60) / 3=60 \%$ \\
\hline
\end{tabular}

Table 5. Correlations of Idea Initiations, Perceived Contributions, and Cognitive Style [N=122]

\begin{tabular}{|l|l|l|l|l|}
\hline $\begin{array}{l}\text { Cognitive Style / } \\
\text { Initiations \& Contributions }\end{array}$ & KAI Total & SO & $\mathrm{E}$ & $\mathrm{R} / \mathrm{G}$ \\
\hline Idea Initiator & 0.026 & -0.030 & 0.042 & 0.062 \\
\hline Avg. Contribution & 0.139 & 0.148 & 0.013 & 0.116 \\
\hline
\end{tabular}

All $\mathrm{p}>0.05$

Cognitive Style Gaps and Perceptions of Ideation Outcomes, Idea Initiation, and Contributions

We continued the investigation of our second research question by investigating the relationship between cognitive gap, changes in perceived ideation outcomes, and perceptions of idea initiation and contribution. The cognitive gap was calculated for each individual by subtracting their own total KAI score from their teammate's score, yielding both positive and negative values. As a means of understanding the general distribution of cognitive gaps within the sample, however, Figure 3 shows the magnitude distribution of cognitive gaps across the entire sample (36 teams). Here, we note that 21 of the 36 teams had cognitive gaps greater than the "justnoticeable difference" of 10 points, but the representation of gaps across the spectrum is uneven.

As shown in Table 6, no significant correlations were found between cognitive gap and the change in students' perceptions of their ideation between the two sessions. In other words, there was no apparent relationship between the cognitive gap between ideation partners and the change in their perceptions about their ideation performance. Likewise, no significant correlation was found between cognitive gap and the perceived difficulty of teaming $(r=-0.021 ; p=0.858)$. While this latter result might seem surprising (we might expect larger cognitive gaps to lead to greater perceived difficulty of working together), the apparent lack of a relationship might be attributed to the fact that the student teams did not interact long enough (only 20 minutes) for the effects of any cognitive gap to be apparent or create discomfort.

Interestingly, a significant $(p \leq 0.05)$ negative correlation was observed between the average perceived contribution per idea and cognitive gap (see Table 7). This relationship shows that in teams where the cognitive gap was large, the more adaptive student (of the pair) tended to feel that they contributed less, while the more innovative student tended to feel that they contributed more. It is important to remember that the average contribution considered here is a perceived measure and may not be indicative of the actual contribution to the team. 
Team Cognitive Gaps

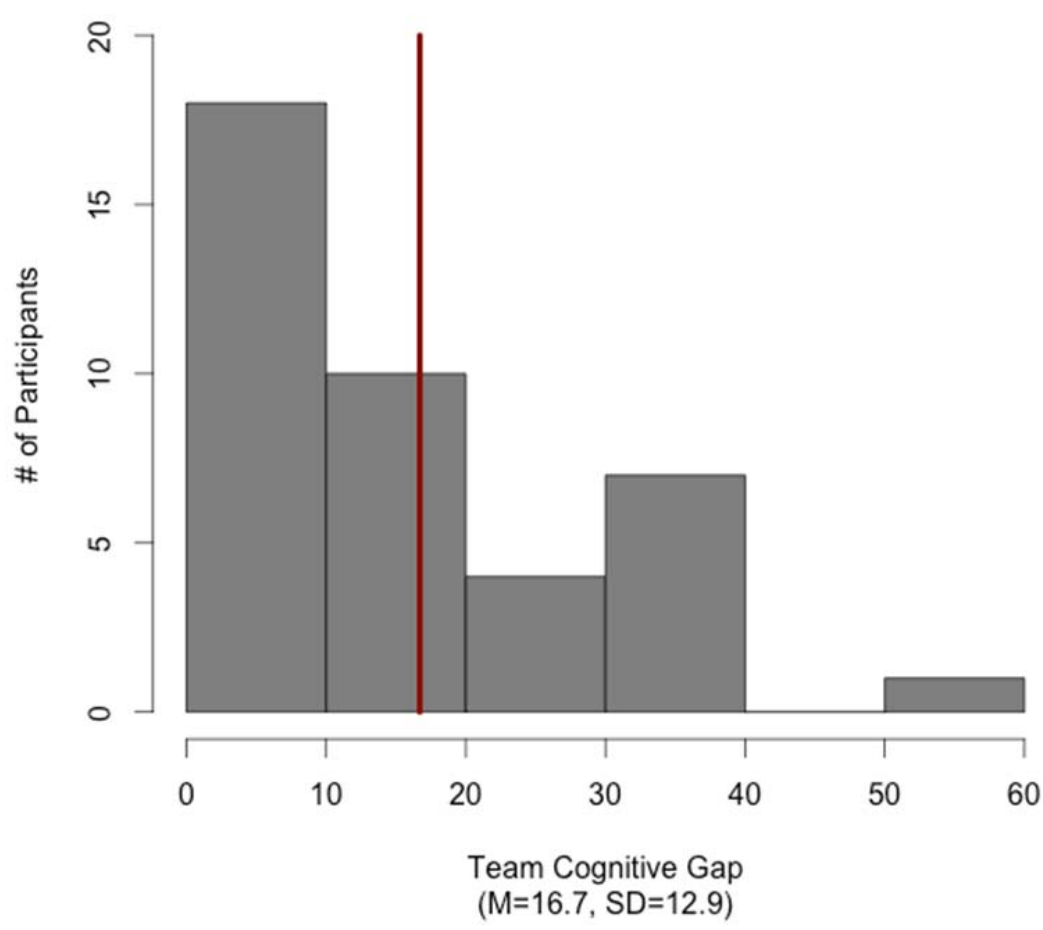

Figure 3. Distribution of Team Cognitive Gaps (magnitude) where Team Cognitive Gap = ABS(Teammate A's Total KAI Score - Teammate B's Total KAI Score)

Table 6. Correlations of Cognitive Gap with Change in Ideation Perceptions [N=74]

\begin{tabular}{|l|l|}
\hline $\begin{array}{l}\text { Cognitive Gap / } \\
\Delta \text { Perceptions }\end{array}$ & Cognitive Gap \\
\hline$\Delta$ Creativity & 0.161 \\
\hline$\Delta$ Diversity & 0.152 \\
\hline$\Delta$ Elaboration & -0.006 \\
\hline$\Delta$ Difficulty & -0.145 \\
\hline
\end{tabular}

Table 7. Correlations of Cognitive Gap with Perceived Contributions $[\mathrm{N}=74]$

\begin{tabular}{|l|l|}
\hline $\begin{array}{l}\text { Cognitive Gap / } \\
\text { Perceived Contributions }\end{array}$ & Cognitive Gap \\
\hline Idea Initiator & -0.046 \\
\hline Avg. Contribution & $-0.237^{*}$ \\
\hline Indicates $\mathrm{p} \leq 0.05$ &
\end{tabular}

Finally, Table 8 shows the correlations between average perceived contribution to ideation and the perceptions of ideation during the teaming session. As opposed to the previous tables, in which the change in perceptions of creativity, diversity, elaboration, and difficulty were considered, only the perceptions from the teaming session (Session 2) were used here. This follows because the contribution data were only meaningful for the teaming session and were not recorded in the individual session. Weak $(|\mathrm{r}|<0.2)$ positive correlations between perceived diversity and difficulty and average perceived contribution indicate that individuals who felt that they contributed more also tended to feel that their ideas were more diverse and that it was more difficult for them to generate ideas. 
Table 8. Correlations of Perceptions of Ideation versus Perceived Contributions [ $\mathrm{N}=202]$

\begin{tabular}{|l|l|l|l|l|l|}
\hline $\begin{array}{l}\text { Perceptions of Ideation / } \\
\text { Perceived Contributions }\end{array}$ & Creativity & Diversity & Elaboration & Difficulty & $\begin{array}{l}\text { Difficulty of } \\
\text { Teaming }\end{array}$ \\
\hline Idea Initiator & -0.024 & 0.107 & 0.036 & -0.009 & -0.121 \\
\hline Avg. Contribution & 0.037 & $0.152^{*}$ & 0.030 & $0.158^{*}$ & -0.130 \\
\hline
\end{tabular}

Indicates $\mathrm{p} \leq 0.05$

\subsection{Conclusions, Implications, and Future Work}

In summary, our results suggest that teaming affects different people in different ways and with respect to different aspects of ideation - and that cognitive style is a relevant factor in these differences. This general statement is based upon the following observations from our data:

- Students' perceptions of the impact of teaming on the creativity, diversity, and elaboration of their ideation outcomes were correlated with cognitive style.

- The more adaptive students (relative to the mean of the sample) tended to feel that their ideas were more diverse in a teaming situation than when they worked alone, whereas the more innovative students tended to feel that their ideas were less diverse.

- Students with more adaptive $\mathrm{E}$ sub-scores tended to perceive their ideas to be more creative, but less elaborate, in a teaming situation, whereas those with more innovative $\mathrm{E}$ sub-scores tended to feel less creative, but more elaborate, when generating ideas in a team.

- As the cognitive gaps of teams increased in magnitude, the more adaptive student on a team tended to rate his/her own contributions to the team lower than those of the more innovative team member.

- Those students who felt that they contributed more to each idea in teaming ideation tended to also feel that they came up with more diverse ideas and that they were more difficult to generate.

While the preliminary nature of this study limits the strength of any conclusions we make, the results do suggest several implications for the engineering classroom, as well as some interesting possibilities for further exploration:

- In the engineering classroom, helping individuals understand how they personally respond to working in teams during ideation will allow students to use teaming ideation to their advantage instead of relying on "one size fits all" approaches.

- Working in teams can force students to work in non-preferred ways; there are advantages, but they may come at a cost, including changes in perceptions of ideation performance that may (or may not) be accurate.

In the future, and as part of a larger and long-term research agenda, we will use more objective metrics for creativity, diversity, and elaboration to determine the actual impact of teaming and cognitive style on ideation performance - and compare these results with students' perceptions. 
We will also conduct the same tasks with large samples to observe the variation and to validate our results. This work has already begun with respect to ideation diversity through our recent investigation of the application and sensitivity of current ideation variety metrics to the effects of cognitive style and the use of design heuristics ${ }^{34}$.

\section{Acknowledgements}

This research was supported by the National Science Foundation through Research in Engineering Education (REE) Grants \#1264715, \#1265018, and \#1264551.

\section{References}

[1] Pauhus, P. B., Dzindolet, M. T., Poletes, G., and Camacho, L. M., 1993, "Perception of Performance in Group Brainstorming: The Illusion of Group Productivity," Pers Soc Psychol Bull, 19(1), pp. 78-89.

[2] Diehl, M., and Stroebe, W., 1987, "Productivity loss in brainstorming groups: Toward the solution of a riddle," Journal of Personality and Social Psychology, 53(3), pp. 497-509.

[3] Mullen, B., Johnson, C., and Salas, E., 1991, "Productivity Loss in Brainstorming Groups: A Meta-Analytic Integration," Basic and Applied Social Psychology, 12(1), pp. 3-23.

[4] Chrysikou, E. G., and Weisberg, R. W., 2005, "Following the wrong footsteps: fixation effects of pictorial examples in a design problem-solving task," J Exp Psychol Learn Mem Cogn, 31(5), pp. 1134-1148.

[5] Laughlin, P. R., Bonner, B. L., and Miner, A. G., 2002, "Groups perform better than the best individuals on Letters-to-Numbers problems," Organizational Behavior and Human Decision Processes, 88(2), pp. 605-620.

[6] Kirton, M. J., 2011, Adaption-Innovation in the Context of Diversity and Change, Routledge, London, UK.

[7] Brophy, D. R., 2001, "Comparing the attributes, activities, and performance of divergent, convergent, and combination thinkers," Creativity Research Journal, 13(3-4), pp. 439-455.

[8] Liu, Y.-C., Chakrabarti, A., and Bligh, T., 2003, "Towards an 'ideal' approach for concept generation," Design Studies, 24(4), pp. 341-355.

[9] Yilmaz, S., Daly, S. R., Jablokow, K. W., Silk, E. M., and Rosenberg, M., 2014, "Investigating impacts on the ideation flexibility of engineers."

[10] Kirton, M. J., 1976, “Adaptors and innovators: A description and measure,” Journal of Applied Psychology, 61(5), pp. 622-629.

[11] Jablokow, K. W., and Kirton, M. J., 2009, Problem Solving, Creativity, and the Level-Style Distinction. In Perspectives on the Nature of Intellectual Styles (L.-F. Zhang and R. J. Sternberg, Eds.)., Springer, New York, NY.

[12] Jablokow, K. W., 2008, "Developing problem solving leadership: a cognitive approach,” International Journal of Engineering Education, 24(5), pp. 936-954.

[13] Defranco, J. F., Jablokow, K., Bilen, S. G., and Gordon, A., 2012, "The impact of cognitive style on concept mapping: visualizing variations in the structure of ideas," American Society for Engineering Education, American Society for Engineering Education.

[14] Jablokow, K. W., and Booth, D. E., 2006, "The impact and management of cognitive gap in high performance product development organizations," Journal of Engineering and Technology Management, 23(4), pp. 313336.

[15] Lindsay, P. R., 1985, “Counselling to resolve a clash of cognitive styles,” Technovation, 3(1), pp. 57-67.

[16] McCarthy, R., 1988, "An investigation of role conflict and coping behaviour in women managers.," MSc Thesis, University of Hertforshire.

[17] Kubeŝ, M., and Spillerova, D., 1992, "Dynamics of innovation: understanding and influencing communication behaviours," Creativity and Innovation Management, 1(1), pp. 33-39.

[18] Rickards, T., and Moger, S. T., 1994, "Felix and Oscar revisited: An exploration of the dynamics of a real-life odd couple work relationship," The Journal of applied behavioral science, 30(1), pp. 108-131.

[19] Hammerschmidt, P. K., 1996, "The Kirton Adaption Innovation Inventory Find Group Problem Solving Success Rates," The Journal of Creative Behavior, 30(1), pp. 61-74. 
[20] McCarthy, R., 1993, "The relationship of individual characteristics of women managers to the pressures experienced at work and choice of coping strategy.," PhD Thesis, University of Hertforshire.

[21] Paulus, P. B., and Yang, H.-C., 2000, "Idea generation in groups: A basis for creativity in organizations," Organizational Behavior and Human Decision Processes, 82(1), pp. 76-87.

[22] Page, S. E., 2007, The Difference: How the Power of Diversity Creates Better Groups, Firms, Schools, and Societies. Princeton, NJ: Princeton University Press., Princeton University Press, Princeton, NJ.

[23] Osborn, A., 1957, Applied Imagination: Principles and Procedures of Creative Problem Solving New York, Scribner.

[24] Geschka, H., Schaude, G. R., and Schlicksupp, H., 1976, "MODERN TECHNIQUES FOR SOLVING PROBLEMS," International Studies of Management \& Organization, 6(4), pp. 45-63.

[25] Van De Ven, A. H., and Delbecq, A. L., 1974, "The Effectiveness of Nominal, Delphi, and Interacting Group Decision Making Processes," The Academy of Management Journal, 17(4), pp. 605-621.

[26] Seda Yilmaz, S. R. D., 2013, "Can experienced designers learn from new tools? A case study of idea generation in a professional engineering team," International Journal of Design Creativity and Innovation.

[27] Steiner, I. D., 1972, Group Processes and Productivity, Academic Press.

[28] Collins, B. E., and Guetzkow, H. S., 1964, A social psychology of group processes for decision-making, Wiley.

[29] Linsey, J. S., Clauss, E. F., Kurtoglu, T., Murphy, J. T., Wood, K. L., and Markman, A. B., 2011, “An experimental study of group idea generation techniques: Understanding the roles of idea representation and viewing methods," Journal of Mechanical Design, 133(3), p. 031008.

[30] Paulus, P. B., Larey, T. S., and Ortega, A. H., 1995, "Performance and perceptions of brainstormers in an organizational setting," Basic and Applied Social Psychology, 17(1-2), pp. 249-265.

[31] Paulus, P. B., 2000, "Groups, teams, and creativity: The creative potential of idea-generating groups," Applied Psychology, 49(2), pp. 237-262.

[32] Linsey, J. S., Tseng, I., Fu, K., Cagan, J., Wood, K. L., and Schunn, C., 2010, “A study of design fixation, its mitigation and perception in engineering design faculty," Journal of Mechanical Design, 132(4), p. 041003.

[33] Parkhurst, H. B., 1999, "Confusion, lack of consensus, and the definition of creativity as a construct," The Journal of Creative Behavior, 33(1), pp. 1-21.

[34] Jablokow, K. W., Teerlink, W., Yilmaz, S., Daly, S. R., Silk, E. M., and Wehr, C., 2015, submitted to ASME International Design Engineering Technical Conferences (IDETC), "Ideation variety in mechanical design: Examining the effects of cognitive style and design heuristics," Boston, MA (under review). 


\section{APPENDIX A (Reflection Survey for the Teaming Ideation Session)}

Your Name:

Problem \#:

For the following questions, think only about the solution ideas that you came up with for this design problem. Do not think about any prior idea generation activity that you may have participated in using a different design problem. Also, do not look back at the problem statement or the solution ideas you generated. Just complete them as best you can from your memory of the activity. Finally, complete the questions in order.

\section{Section 1}

1. On a scale from 1 to 7 , how creative do you feel that your ideas were? Circle one number.

\begin{tabular}{|c|c|c|c|c|c|c|}
\hline 1 & 2 & 3 & 4 & 5 & 6 & 7 \\
\hline $\begin{array}{c}\text { Not } \\
\text { creative }\end{array}$ & & & Neutral & & & $\begin{array}{l}\text { Very } \\
\text { creati }\end{array}$ \\
\hline
\end{tabular}

2. On a scale from 1 to 7 , how diverse, or different from each other, do you feel that your ideas were? Circle one number.

\begin{tabular}{c|c|c|c|c|c|c|}
\hline 1 & 2 & 3 & 4 & 5 & 6 & 7 \\
\hline $\begin{array}{c}\text { Not } \\
\text { diverse }\end{array}$ & Neutral & Very \\
diverse
\end{tabular}

3. On a scale from 1 to 7, how elaborate, detailed, or "fleshed-out," do you feel that your ideas were? Circle one number.

\begin{tabular}{|c|c|c|c|c|c|c|}
\hline 1 & 2 & 3 & 4 & 5 & 6 & 7 \\
\hline $\begin{array}{c}\text { Not } \\
\text { elaborate }\end{array}$ & Neutral & $\begin{array}{c}\text { Very } \\
\text { elaborate }\end{array}$
\end{tabular}

4. What existing solutions for this particular design problem were you aware of or familiar with prior to this activity that may have influenced the solutions you came up with? Please explain. 


\section{Section 2}

5. Imagine that you asked a co-worker to generate additional solution ideas for this same design problem. In a few sentences, explain to your co-worker what to focus on when coming up with their own solution ideas.

\section{Section 3}

6. On a scale from 1 to 7 , how easy or difficult was it for you to come up with design ideas? Circle one number.

\begin{tabular}{c|c|c|c|c|c|c|}
\hline 1 & 2 & 3 & 4 & 5 & 6 & 7 \\
\hline $\begin{array}{c}\text { Very } \\
\text { difficult }\end{array}$ & Neutral & $\begin{array}{l}\text { Very } \\
\text { easy }\end{array}$
\end{tabular}

7. Please explain your choice for the previous question. What made it easy or difficult for you to come up with design ideas?

Page 2 - Please turn to next page. 


\section{Section 4}

8. On a scale from 1 to 7 , how much did the written description of the design task encourage you to come up with design ideas that were familiar versus ideas that were new? Circle one number.

\begin{tabular}{|c|c|c|c|c|c|c|}
\hline 1 & 2 & 3 & 4 & 5 & 6 & 7 \\
\hline $\begin{array}{c}\text { The } \\
\text { written } \\
\text { description } \\
\text { encouraged } \\
\text { very new } \\
\text { ideas }\end{array}$ & & & $\begin{array}{r}\text { Th } \\
\text { writt } \\
\text { descrip } \\
\text { didn } \\
\text { encou } \\
\text { one so } \\
\text { idea } \\
\text { anotl }\end{array}$ & & & $\begin{array}{l}\text { The } \\
\text { written } \\
\text { description } \\
\text { encouraged } \\
\text { very } \\
\text { familiar } \\
\text { ideas }\end{array}$ \\
\hline
\end{tabular}

9. Think about the written description of the design task. What kinds of ideas (if any) do you feel the description encouraged or discouraged you to come up with? Please explain.

10. On a scale from 1 to 7 , how much did the amount of information given in the written description of the design task make it easy or difficult for you to come up with design ideas? Circle one number.

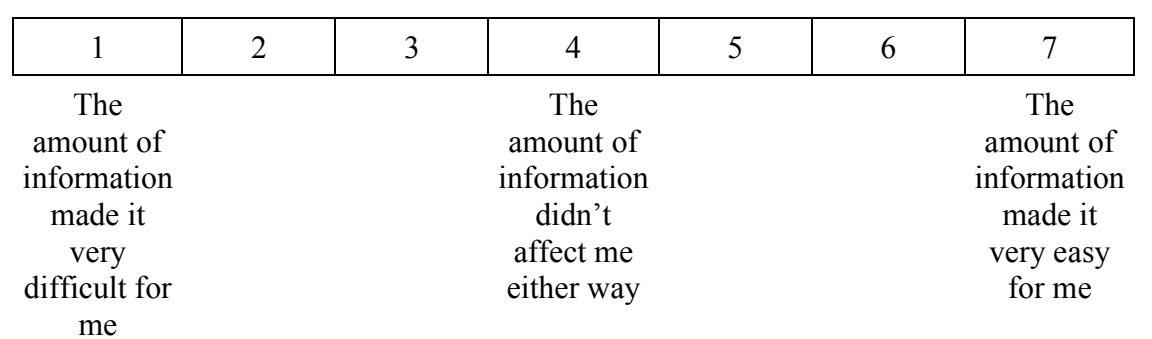

Page 3 - Please turn to next page. 


\section{Section 5}

11. On a scale from 1 to 7 , how much did working in a team make it easy or difficult for you to come up with design ideas? Circle one number.

\begin{tabular}{|c|c|c|c|c|c|c|}
\hline 1 & 2 & 3 & 4 & 5 & 6 & 7 \\
\hline $\begin{array}{c}\text { Working } \\
\text { in a team } \\
\text { made it } \\
\text { very } \\
\text { difficult }\end{array}$ & & & $\begin{array}{l}\text { Work } \\
\text { in a te } \\
\text { didn } \\
\text { affect } \\
\text { either }\end{array}$ & & & $\begin{array}{c}\text { Working } \\
\text { in a team } \\
\text { made it } \\
\text { very easy } \\
\text { for me }\end{array}$ \\
\hline
\end{tabular}

12. How did working in a team impact your process for generating ideas and/or the ideas you generated? Please explain.

13. Rank the ideas that you generated from the one you think is most likely to be successful (1) to the one you think is least likely to be successful. Also, circle your favorite idea.
a. Ranking Idea \#
1
b. For the idea that you ranked as most likely to be successful (1), explain why.
2
3
4
5
6
c. For the idea that you ranked as least likely to be
7 successful, explain why.
8
9
10

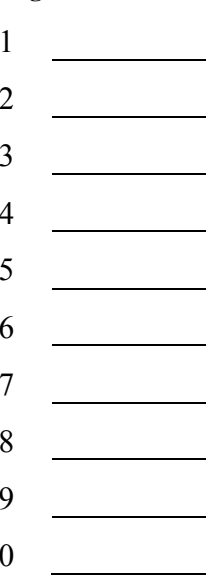

Page 4 - Please turn to next page. 


\section{Section A}

A. What is your gender?
$\square$ Male
$\square$ Female
$\square$ Other

B. What is your age?

C. Please select all races that apply to you:

$\square$ American Indian or Alaska Native

Native Hawaiian or Pacific Islander

$\square$ Asian

White

Other

D. Are you Hispanic or Latino/a?

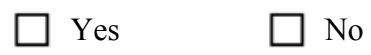

E. What is the highest year in school that you have successfully completed?

F. What is your intended major in college?

\section{Section B}

G. Would you like a photocopy of the design solutions you created in this session returned to you?

$\square$ No thanks. I don't need a copy.

Yes, please make a photocopy for me.

H. We would like to use the ideas you generated to help us improve engineering education. Do you want your designs to be included in a research study on how engineering students generate design ideas (your real name will be removed from the sheets and never be used)?

Yes, I am happy to help with research to improve engineering education. $\square$ No, I do not want my work to be included as part of research.

When you have completed this reflection survey, please make sure your idea sheets are stacked in order (Idea \#1 on top), with the design task description on top, and then place this reflection survey on the bottom of that stack. Please put the entire stack back in the folder provided. 


\section{APPENDIX B (Idea Sheet for All Sessions)}

Idea Generation

Idea Sheet

Your Name:

Problem \#:

Idea \#:

Idea Drawing: Sketch your solution idea in the box below.

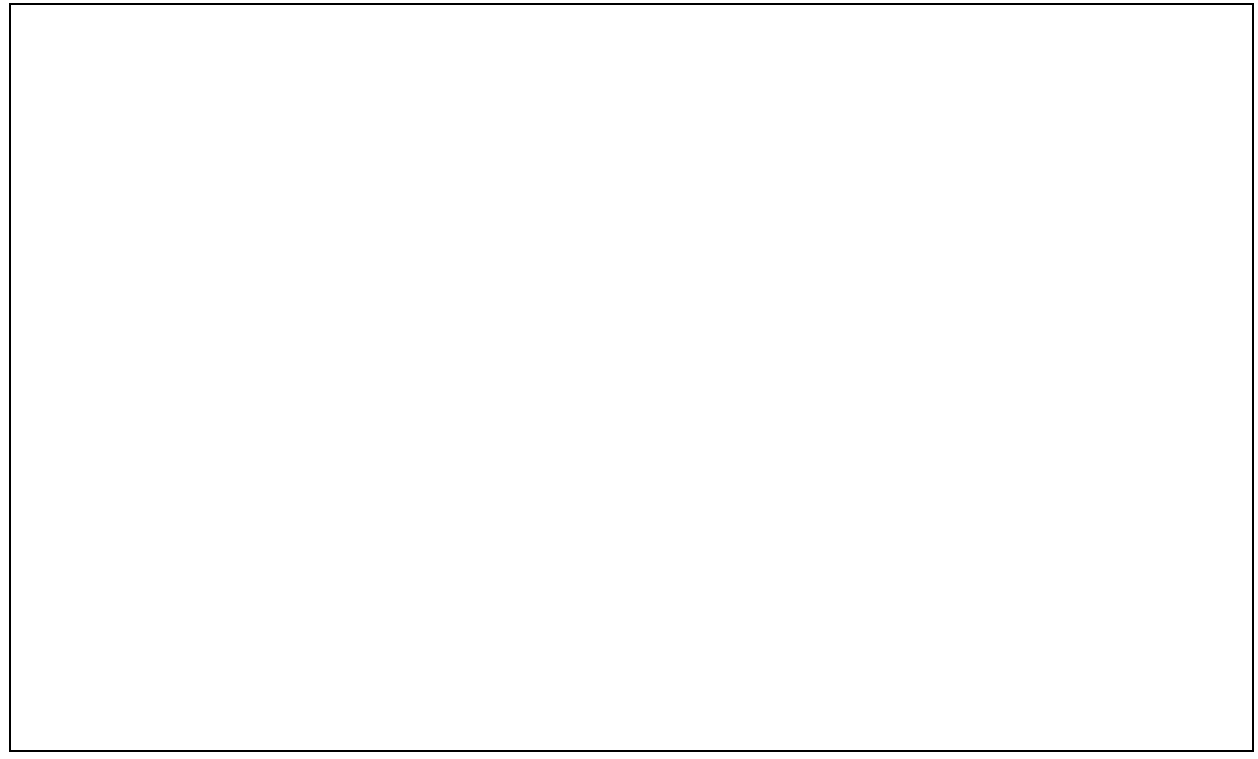

Idea Description: Describe the solution idea. How does it work? What are the features, mechanisms, and details?

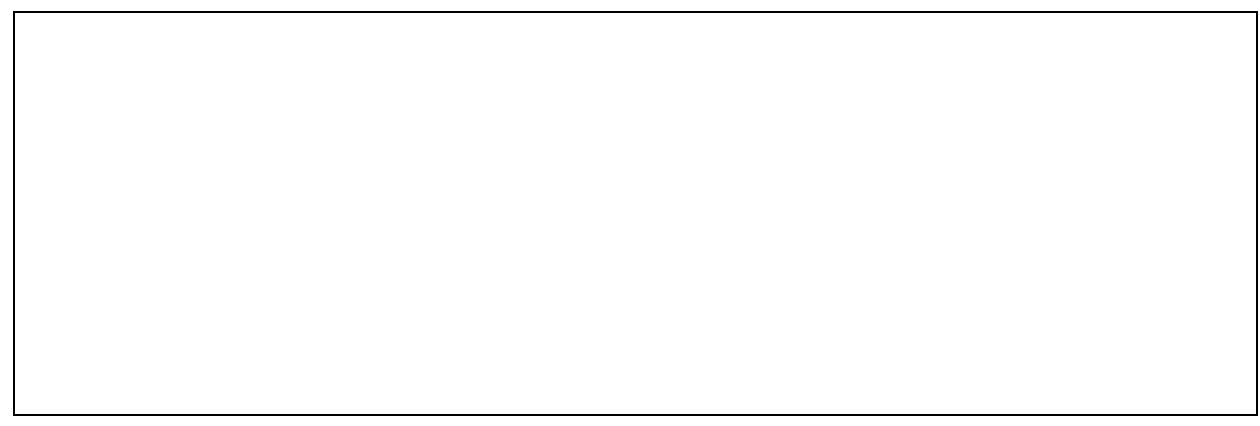

Teamwork: Who initially brought up this idea? (Circle one.) Me Another Team Member

Identify to what extent you feel this idea was generated and developed by you, by your team members, or by some combination. (Circle the best response.)

$$
0 \cdots{ }_{10} \cdots{ }_{20} \cdots{ }_{30} \cdots{ }_{40} \cdots_{50} \cdots{ }_{60} \cdots{ }_{70} \cdots{ }_{80} \cdots 90 \cdots 100
$$

This idea was entirely

My team members and I

worked on this idea equally

This idea was entirely mine 